\title{
MICRODOSIMETRIC SPECTRA MEASUREMENTS OF JANUS NEUTRONS
}

\author{
I. R. Marshall and F. S. Williamson \\ Division of Biological and Medical Research \\ Argonne National Laboratory \\ 9700 South Cass Avenue \\ Argonne, Illinois 60439 (USA)
}

\section{DISCIAIMER}

This report was prepared as an account of work sponsored by an agency of the United States Government. Neither the United States Government nor any agency thereof, nor any of their employees, makes any warranty, express or implied, or assumes any legal liability or responsibility for the accuracy, completeness, or usefulness of any information, apparatus, product, or process disclosed, or represents that its use would not infringe privately owned rights. Reference herein to any specific commercial product, process, or service by trade name, trademark, manufacturer, or otherwise does not necessarily constitute or imply its endorsement, recommendation, or favoring by the United States Government or any agency thereof. The views and opinions of authors expressed herein do not necessarily state or reflect those of the United States Government or any agency thereof. 
Neutron radiation from the JANUS reactor at Argonne National Laboratory is being used with increasing frequency for major biological experiments. The fast neutron spectrum has a Kerma-weighted mean energy of $0.8 \mathrm{MeV}$ and $1 \mathrm{ow}$ gamma-ray contamination. In 1984 the JANUS fission converter plate of highly enriched uranium was replaced by one made of low-enriched uranium.

We recorded microdosimetric spectra at several different positions in the high-flux irradiation room of JANUS before the change of the converter plate. Each set of measurements consisted of spectra taken at three different site diameters $(0.5,1.0$, and $5.0 \mu \mathrm{m})$ and in both "attenuator up" and "attenuator down" configurations. At two conventional dosinetry reference positions, two sets of measurements were recorded. At three biological reference positions, measurements simulating several biological irradiation conditions, were taken. The dose rate at each position was estimated and compared with dose rates obtained previously by conventional dosimetry. Comparison of the different measurements showed no major change in spectra as a function of position or irradiation condition.

First results from similar sets of measurements recorded after the installment of the new converter plate indicate no major change in the spectra. 


\section{INTRODUCTION}

The JANUS reactor has been used for a number of biological experiments over the last several years. At the beginning of 1984 we were notified that the Fission Converter Assembly ( $F C A$ ), which was composed of highly enriched uranium, had to be replaced with an assembly constructed of low enriched uranium. It is essential not only to repeat all the spectrometry and dosimetry studies conducted more than a decade ago, but also to design and perform studies that will reveal any differences in biological response due to changes in the neutron source. This paper describes only those microdosimetric measurements made before and after the FCA replacement.

The JANUS High Flux Room

The room in which all biological experimests are carried out is the High Flux Room, which is approximately $4.4 \mathrm{mlong}, 2 \mathrm{~m}$ wide and $2 \mathrm{~m}$ high. It is used for the irradiation of up to 400 mice in a single loading and also for cell culture experiments.

The reactor has a fully enriched $235 \mathrm{U}$ core, moderated by light water, and runs at variable power levels up to $200 \mathrm{~kW}$ thermal. The core is situated between two graphite thermal columns, each of which ends in a large port through which the neutrons pass into an irradiation room. The reactor core is asymmetrically placed between the two ports so that the emerging thermal neutron fluxes differ by a factor of approximately 3000. At the present time, only one of two irradiation rooms, the High Flux Room, is used for radiation biology. Pneumatically actuated shutters inside the port allow the room to be used for setting up apparatus while the reactor is operating, with an exposure rate to personnel of less than $0.5 \mathrm{mSv} \cdot \mathrm{h}^{-1}$ from fast neutrons. When the 
shutters are opened, a curved FCA, approximately $1 \mathrm{~m}$ high by $3.5 \mathrm{~m} \mathrm{long}$, is raised into the port. The old $F C A$ contained enriched $235 \mathrm{U}$, which interacts with the thermal neutrons from the reactor to produce fission neutrons. The fission neutrons then pass through $5 \mathrm{~cm}$ of lead into the irradiation room. The new FCA contains the same mass of $235 \mathrm{U}$ diluted with approximately $130 \mathrm{~kg}$ of $238 U$.

The High Flux Room is lined with $10 \mathrm{~cm}$ of lead to reduce the exposure rate from gamina rays produced by neutron interactions in the concrete. In addition, there is a layer of borated hardboard, 10-cm thick, between the lead and the concrete on the walls and floor and a layer of special borated-bauxite concrete, $25 \mathrm{~cm}$ thick, above the lead ceiling (Figure 1). These borated materials effectively reduce the flux of thermal neutrons in the room caused by the moderation of fast neutrons in the concrete. A Boral plate across the port absorbs unconverted thermal neutrons from the reactor, and a graded attenuator plate between the thermal column and the converter plate can be used, optionally, to optimize the neutron kerma distribution in the room. (1) 


\section{MATERIALS AND METHODS}

The proportional counter used for the measurements is a $12.7 \mathrm{~mm}$ diameter spherical tissue-equivalent linear energy transfer (LET) counter manufactured by Far West Technoiogy ${ }^{*}$ and follows the specifications of H. H. Rossi of Columbia University. The counter has an internal $244 \mathrm{Cm}$ - alpha source with a mean energy of $5.8 \mathrm{MeV}$, which is used for all the calibrations. Measurements made before the converter plate change used only methane tissue equivalent (TE)-gas. First measurements after the change were made with both methane and propane TE-gas. The composition of the methane TE-gas was $64.4 \%$ methane, $32.4 \% \mathrm{CO}_{2}$, and $3.2 \% \mathrm{~N}_{2}$. The composition of the propane TE-gas is $55 \%$ propane, $39.6 \% \mathrm{CO}_{2}$, and $5.4 \% \mathrm{~N}_{2}$. The correction factors for the $\mathrm{W}$-value, the average energy required to produce an ion pair, and the stopping power value used were taken from $M$. Varma (2). For methane TE-gas, the correction factor for the W-value was 0.97 for the neutron measurements and 1.06 for gamma-ray measurements; for the propane TE-gas, the corresponding values are 0.99 for the neutron measurements and 1.04 for gamma-ray measurements. The stopping power for the $5.8 \mathrm{MeV}$ alpha particles was 81.7 for the methane TE-gas and 85.1 for the propane TE-gas.

For the measurements a continuous flow system was used similar to the one described by H. H. Rossi(3). The system is pumped for about 24 hours, then a steady flow is maintained, keeping the pressure inside the counter at the required value for 12 hours before any measurement is made. This procedure ensures that the plastic walls are saturated with tissue-equivalent gas. Measurements can thus be carried out over many hours and even days with less

\footnotetext{
* Far West Technology, Inc., 330 D South Kellogg, Goleta, CA 93017.
} 
than a $1 \%$ change in the peak position. Each measurement consisted of at least three different gain settings. The background (noise) spectrum was measured separately. A specially written computer program combines the different gain settings, subtracts the noise spectrum, performs alternative extrapolations to zero event size, then calculates microdosimetric values, the dose rate, the percentage of the low-LET contribution, and finally produces normalized graphs.

Three different extrapolation procedures were performed:

1. Zero slope extrapolation from the lowest measured y value to zero event size.

2. Linear negative slope extrapolation to $30 \mathrm{ev}$, then zero slope extrapolation to zero event size.

3. Exponential extrapolation to $30 \mathrm{eV}$, then zero slope extrapolation to zero event size.

For the extraplation to $30 \mathrm{eV}$, between 40 and several hundred points were used, depending on the highest gain setting applied.

Because the microdosimetric system was completed only shortly before the converter plate change, at a time when the computer program had not been written, al1 measurements were taken without concurrent data analysis. Later the results showed an unfortunately high noise level (about $0.55 \mathrm{KeV}_{. \mu}{ }^{-1}$ ). This level has so far been reduced to about $0.3 \mathrm{KeV}_{. \mu} \mu^{-1}$. This reduction in noise was achieved by keeping the connection between the proportional counter and the preamplifier as short as possible and by removing the input coupling capacitor and the protective diodes across the input field effect transistor (FET) in the ORTEC 142PC preamplifier.

Measurements were also made with a ${ }^{60} \mathrm{Co}$ gamma source. 
The measurements of the JANUS neutrons before the FCA change were made at three different site diameters: $0.5,1.0$, and $5.0 \mu \mathrm{m}$. The first measurements after the FCA change were resti icted to a site diameter of $1.0 \mu \mathrm{m}$. Most of these measurements were made with methane TE-gas to allow for a direct comparison with the original data, however, several measurements were later repeated with propane-TE gas.

The JANUS neutron microdosimetric spectrum was measured at five different positions within the High Flux Room of the reactor and under several different conditions (Figure 1). The conditions were as follows: attenuator up vs. attenuator down, methane vs. propane TE-gas, three different site diameters; with and without phantoms. At position 0-0-100 (see Figure 1) the change in spectrum as a function of water depth was recorded. At position 8 , which is one of the mouse irradiation positions, a TE plastic cap made from A- 150 tissue equivalent plastic (4) was placed on the proportional counter, which in one case had similar mass and in the other case had a similar volume to a mouse. In positions 5 and 8 the measurements were made with mouse phantoms in position under circumstances simulating standard exposure conditions. 


\section{RESULTS}

The problem encountered with noise level required careful evaluation of the results. At these low y-values, nearly all of the energy deposition can be attributed to gamma rays. A ${ }^{60} \mathrm{Co}$-gamma spectrum was therefore taken to determine the best extrapolation.

Cobalt gamma rays

The spectra were taken at a site diameter of $1 \mu \mathrm{m}$ with both propane and methane TE-gas. The lowest measured $y$-value for propane TE-gas was $0.24 \mathrm{KeV}_{.} \mu^{-1}$. From this data, the $\bar{y}_{F}$, (frequency mean lineal energy), $\bar{y}_{D}$ (dose mean lineal energy) as defined in the ICRU report $36^{(5)}$, and the dose rate were calculated by using zero slope, linear, and exponential extrapolations. Both the linear and the exponential extrapolation dose rate estimates were close to the dose rate determined from an ionisation chamber measurement. The $\bar{y}_{F}$ and the $\bar{y}_{D}$ determined from the exponential extrapolation, however, agreed better with the values reported in the literature $(5,6)$. By increasing the cutoff level stepwise from 0.24 to $1.14 \mathrm{KeV}_{. \mu^{-1}}$ and comparing the different extrapolation results, we hoped to determine which of the extrapolations was the most reliable. The extrapolated values are given in Table 1 together with the methane TE-gas data and the dose rate determined by the ionisation chamber. Our results indicate that exponential extrapolation offers the best prediction of experinental data. However, none of the extrapolation procedures was able to predict accurately the parameters from high cutoff levels. The difference $i_{i l}$ dose-rate estimates between a cutoff at 0.24 vs. a cutoff at $1.14{\mathrm{KeV} . \mu^{-1}}^{-1}$ resulted in an underestimation of $22 \%$ for exponential, $32 \%$ for linear, and $38 \%$ for zero slope extrapolations. The $\bar{y}_{F}$ and $\bar{y}_{D}$ results of the

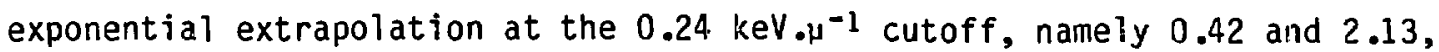


respectively, are in good agreement with generally reported res'1ts. In the following discussion, therefore, only linear and exponential extrapolations will be compared.

\section{JANUS Neutrons}

The results of the JANUS neutron measurements are given in Tables 2,3 , and 4 for the three site diameters and the different positions inside the High Flux room. In Table 2, which represents measurements at $1.0 \mu \mathrm{m}$ site diameter, measurements made in 1984 are shown together with measurements made in 1985. The $y$-spectrum was separated into two components, low LET and medium-to-high LET. The $\bar{y}_{F}, \bar{y}_{D}$ and individual dose rates were calculated for $y$ separation values ranging from 4 to $8 \mathrm{KeV} . \mu^{-1}$. The low LET contribution to the total dose increased from 4 to $5.5 \%$ over this range. The dividing $y$-value was chosen to be $6 \mathrm{KeV} . \mu^{-1}$, which is between the value used by Booz and Poli (7) $\left(3.5 \mathrm{KeV}_{. \mu^{-1}}\right)$ and the one used by Dicello et al. (8) $\left(10 \mathrm{KeV}_{. \mu^{-1}}\right)$. At this value, the contribution to the dose from gamma rays and protons is similar. At the $1 \mu \mathrm{m}$ site diameter before the FCA replacement the values for the 1 owLET component were $\bar{y}_{\bar{r}}=0.61 \pm 0.14$ and $\bar{y}_{D}=1.81 \pm 0.40$ for the 1 inear extrapolation and $\bar{y}_{F}=031 \pm 0.09$ and $\bar{y}_{D}=1.29 \pm 0.43$ for the exponential extrapolation. After the change, the corresponding values for linear extrapolation were $\bar{y}_{F}=0.40 \pm 0.08$ and $\bar{y}_{D}=1.49+0.25$. For exponential extrapolation $\bar{y}_{F}=0.18 \pm 0.05$ and $\bar{y}_{D}=1.0 \pm 0.28$. These values were compared with the corresponding values for ${ }^{60} \mathrm{Co}$ gamma rays between $0-6 \mathrm{KeV} . \mu^{-1}$, which were $\bar{y}_{F}=0.47$ and $\bar{y}_{D}=1.45$ (1 inear extrapolation) and $\bar{y}_{F}=0.38$ and $\bar{y}_{0}=1.39$ (exponential extrapolation) to identify the low-LET component of the spectrum. The values for the medium-to-high LET component were: $\bar{y}_{F}=41.9 \pm$ 1.8 and $\bar{y}_{D}=65.1 \pm 2.9$. 
From Tables 2-4, we can see a major prob?em with the low LET extrapolation. For the dose rates for pure ${ }^{60} \mathrm{Co}$-gamma radiation, the maximum difference between low and high cutoff level was between 22 and $38 \%$. For the JANUS neutron radiation, the low LET dose rate difference is, in many instances, much higher.

In Table 5, the dose rates determined from ionisation chamber monitor readings are given for the different irradiation positions and for the attenuator up and down positions, as well as for different reactor power levels. The dose rates determined from microdosimetric calculatious (Tables 2-4) average about $9 \%$ lower for the 1 and $0.5 \mu \mathrm{m}$ site diameter data. For the $5.0 \mu \mathrm{m}$ site diameter, they are about $40 \%$ lower.

Figure 2 (a and b) illustrates several dose distributions at $1 \mu \mathrm{m}$ site diameter at different positions inside the room before and after the converter plate replacement. The only change observed in the new distribution was the shift to lower values for the low LET component, which could be consistent with an increase in the energy of the gamma radiation. This phenomenon will be studied further. Otherwise, there was no change in the dose distribution as a function of position or condition of irradiation. Figure 3 gives representative dose distributions at 0.5 and $5.0 \mu \mathrm{m}$ site diameters. These distributions were also rather consistent.

At position 0-0-100, we took measurements inside a $16 \mathrm{~cm}$ water cube using a site diameter of $1.0, \mathrm{~m}$. The effect on microdosimetric distribution is shown in Figure 4 and Table 2. There is a large increase in gamma-ray contribution to the dose as a function of water depth. The gamma-ray contribution determined from the microdosimetric measurements at depths $1,5,10$, and $15 \mathrm{~cm}$ were compared with ion-chamber measurements reported in 1972 (1). The gammato-neutron dose ratio calculated from the individual measured contribution to 
Marshall and Williamson

$-11-$

the dose agrees well with the gamma-to-neutron dose determined from the microdosimetric measurements. This figure shows the ratio of gamma-to-neutron dose while the table presents the percentage low LET component as determined from the ratio to the total dose. The gamma dose contribution goes through a maximum in the middle of the cube. The increase in neutron contribution at $15 \mathrm{~cm}$ depth is due to the contribution of backscattered neutrons from the lead wall. The neutron and gamma dose rates in the figure are values obtained from the ionisation chamber measurements at a reactor power of $200 \mathrm{~kW}$. 


\section{DISCUSSION}

The most important result of this investigation is the lack of any significant change in the microdosimetric distribution as a function of position inside the JANUS High Flux room. Previous measurements of neutron energy spectrum with 500 mouse phantoms in a different geometry (9) indicate the effects of neutron scatter by the phantoms. Such a shift in neutron energies might be expected to have a negligible effect on biological response, and this is confirmed by microdosimetry. The TE-plastic cap, with which the counter has been covered, also did not introduce any large change, indicating that the mass of a mouse is not sufficient to perturb the spectrum significantly. No differences were observed in the spectra measured inside the incubator and that measured with no incubator.

The first results after the FCA change seem to indicate a change in the low-LET distribution. The nature of the change points to an increase in the gamma-ray energy. We plan to measure the influerce of the converter plate on the microdosimetric gamma-ray distribution by lowaring the converter plate out of the neutron beam.

The only observation which differed significantly from the rest was that taken inside the water phantom. However, this difference was in the relative gamma-ray contribution and not in the spectral distribution itself. For irradiation of large animals, however, this factor should be considered. The $\bar{y}_{D}$ values calculated from the spectra above $6 \mathrm{KeV}_{\cdot \mu^{-1}}$, compare well with the other $1.0 \mu \mathrm{m}$ site results. The $\vec{y}_{F}$ and $\bar{y}_{D}$ values determined from the spectra below $6 \mathrm{KeV} . \mu^{-1}$ are similar to ${ }^{60} \mathrm{Co}$ gamma-ray values in the same microdosimetric range. The lack of change in the intermediate LET distribution might be attributed to the broad neutron energy distribution where small changes in 
this specirum will not produce a significant change in the microdosimetric distribution.

The large variation in the predicted low-LET contribution to the dose and its strong dependence on the lowest $y$-value measured do not allow for a conclusive estimate of the gamma-ray component. The mean values determined are, however, close to the $3-6 \%$ estimated by ionisation chamber measurements.

The spectra reported here agree quite well with two previous measurements made by Borak and Stinchcomb, one in air and one in a water cube (10). They compared measurements with calculations derived from the neutron energy spectrum. They concluded that due to stoppers and starters especially from the heavy ion recoils, the dose from these high LET particles will be underestimated. However, for large site diameter simulation, this problem will extend into the intermediate LET region. The maximum $L_{\alpha}$ of protons is about $85 \mathrm{KeV} \cdot \mu^{-1}$, which results in a $y_{\max }$ of about $128 \mathrm{KeV}_{\cdot \mu} \mu^{-1}$ (3). Thus, for site diameters larger than $1 \mu \mathrm{m}$, many protons, which are the main contributors to the dose, may not always traverse the counter and will therefore give rise to stopping and starting particles that are incorrectly analysed. This factor might explain the very large difference in dose rate estimate between ionisation-chamber measurements and microdosimetric calculations for the $5 \mu$ site diameter.

Furthermore, the difference in composition between wall and gas, especially for propane TE-gas (11) will affect the charged particle production spectra, since there is more carbon and less oxygen in the wall than in the gas.

Additionally, for the ion-chamber dosimetry, a variable W-value was used, while in this case a constant $W$-value was applied. It should be noted that all JANUS dosimetry is, at present, undergoing a major revision to incorporate 
currently recommended $W$-values and to reconcile measurements made with various ionisation chambers over a time span of 20 years. It is thus too early to draw strong inferences from comparison of microdosimetric and ionisationchamber measurements.

Generally, the results of the 0.5 and $1.0 \mu \mathrm{m}$ site diameter measurements are very encouraging. The advantage of microdosimetric spectrum measurements is that in addition to being able to estimate the dose rate and the 1 ow LET component one can obtain spectral distribution information, which is of great importance for biological measurements. However, the extrapolation to zero event size must be more carefully investigated. It is definitely recommended that every microdosimetric measurement be accompanied by conventional dosimetric measurements to provide a positive control of the results. 


\section{ACKMONLEDGEMENTS}

The authors would like to thank G. Holmblad and J. Trier for their excellent assistance and G. G. Fox and A. Shirvin for the operation of the JANUS reactor facilities.

This research was supported by the $U$. S. Department of Energy under contract No. W-31-109-ENG-38. 


\section{REFERENCES}

1. Williamson, F. S. and Frigerio, N. A. Field Mapping and Depth Dosimetry in the Janus High Flux Irradiation Room. - A Fast Neutron Facility for Biological Research. First Symposium on Neutron Dosimetry in Biology and Medicine, EUR-4896-dfe, CID, Luxembourg, 743-755, 1972.

2. Varma, M. N. Calibration of Proportional Counters in Microdosimetry. Proceedings of the Eighth Symposium on Microdosimetry, Juelich, EUR 8395, 1983.

3. Rossi, H. H. Microscopic Energy Distribution in Irradiated Matter. Radiation Dosimetry, 2nd Edition, Volume 1, Edited by F. H. Attix and W. C. Roesch, 43-92, 1968.

4. J. B. Smathers, Y. A. Otte, A. R. Smith, P. R. Almond, F. H. Attix, J. J. Spokas, W. M. Quam, L. J. Goodman. Composition of A-150 TissueEquivalent Plastic. Medical Physics, Vol. 4, No. 1, 74-77, 1977.

5. Microdosimetry. ICRU Report 36,1983.

6. Booz, J. Microdosimetric Spectra and Parameters of Low LET Radiation. Proceedings of the Fifth Symposium on Microdosimetry, EUR 7147, 311-345, 1976.

7. Booz, J. and Poli, A. Evaluation of the Mean Quality Factor of Mixed Neutron-Gamma Radiations from Microdosimetric Spectra. Proceedings of the Eigth Symposium on Microdosimetry, Juelich, EUR 8395, 237-261, 1983.

8. Dicello, J. F., Gross, S., Kraljevic, U. Radiation Quality of Cal iforni um-252. Phys. Med. Biol., 1972, Vol 17, No. 3, 345-355.

9. Bennet, E. J., Yule, T. J. A Neutron Spectrum Map of the JANuS Irradiation Facility Using Proton-Recoil Proportional Counters. Radiat. Res. 50(2) 219-233 (1972). 
10. Borak, T. B., and Stinchcomb, T. G. Calculations of Charged -Particle Recoils, Slowing-down Spectra, LET and Event-size Distributions for Fast Neutrons and Comparisons with Measurements. Phys. Med. Biol. 24(1) 18-36 (1979).

11. Srdoc, D. Experimental Technique of Measurement of Microscopic Energy Distribution in Irradiated Matter Using Rossi Counters. Radiat. Res. $\underline{43}$, 302-319 (1970). 


\section{LEGENDS}

Table 1. Microdosimetric values and dose rate estimates for different extrapolation procedures as a function of $y-v$ alue cutoff for ${ }^{60}$ Co-gamma rays.

Table 2. Summary of microdosimetric values for linear and exponential extrapolation for $1.0 \mu \mathrm{m}$ site diameter.

Table 3. Summary of microdosimetric values for linear and exponential extrapolation for $0.5 \mu \mathrm{m}$ site diameter.

Table 4. Summary of microdosimetric values for linear and exponential extrapolation for $5.0 \mu \mathrm{m}$ site diameter.

Table 5. Dose rate estimates from ionisation chamber monitor readings for the different positions and conditions inside the JANUS High Flux Room.

Figure 1. Horizontal section of the JANUS High Flux Room. The five different measurement positions are showm. The open rectangles indicate the mouse frames.

Figure $2(a+b)$. The dose distributions for $1 \mu \mathrm{m}$ site diameter as a function of position inside the High Flux Room and for different irradiation conditions.

Figure 3. The dose distributions for 0.5 and $5.0 \mu \mathrm{m}$ site diameter.

Figure 4. The gamma-to-neutron dose ratio. A comparison between ionisation chamber measurements and microdos'metric meausrements. The solid triangles in the gamma-to-neutron dose rate curve represent the microdosimetric results. 


\begin{tabular}{|c|c|c|c|c|c|c|c|c|c|}
\hline \multirow[b]{2}{*}{$\begin{array}{l}\text { Lowest } \\
y \text {-Value }\end{array}$} & \multicolumn{3}{|c|}{ Zero Slope Extrapol. } & \multicolumn{3}{|c|}{ Linear Extrapol. } & \multicolumn{3}{|c|}{ Exponential Extrapol. } \\
\hline & $\overline{y_{F}}$ & $\overline{y_{D}}$ & $\begin{array}{l}\text { Dose Rate } \\
\left(\text { cGy } \text { min }^{-1}\right)\end{array}$ & $\overline{y_{F}}$ & $\bar{y}_{D}$ & $\begin{array}{l}\text { Dose Rate } \\
(c G y \text { min } \\
\text {-1) }\end{array}$ & $\overline{y_{F}}$ & $\overline{y_{D}}$ & $\begin{array}{l}\text { Dose Rate } \\
\left(c G y \text {. } \text { min }^{-1}\right)\end{array}$ \\
\hline
\end{tabular}

a) Prodane TE-gas - Feb. 1985

$\begin{array}{llllllllll}0.24 & 0.57 & 2.26 & 0.066 & 0.52 & 2.23 & 0.067 & 0.42 & 2.13 & 0.070 \\ 0.34 & 0.67 & 2.39 & 0.062 & 0.59 & 2.32 & 0.064 & 0.45 & 2.18 & 0.068 \\ 0.54 & 0.90 & 2.68 & 0.054 & 0.76 & 2.57 & 0.057 & 0.58 & 2.39 & 0.062 \\ 0.74 & 1.08 & 2.90 & 0.050 & 0.87 & 2.68 & 0.054 & 0.64 & 2.48 & 0.059 \\ 0.94 & 1.27 & 3.11 & 0.045 & 0.96 & 2.87 & 0.051 & 0.71 & 2.57 & 0.051 \\ 1.14 & 1.46 & 3.33 & 0.042 & 1.13 & 3.05 & 0.046 & 0.81 & 2.72 & 0.053\end{array}$

b) Methane TE-gas - April 1984
$0.546 \quad 0.90$
$2.74 \quad 0.063$
$0.79 \quad 2.65$
0.065
$0.58 \quad 2.41$
0.0722

c) Ionisation chamber monitor reading:

April 1984: 0.0742 cGy.min ${ }^{-1}$

Feb. 1985: 0.0674 cGy.min-1 
table 2.

1 MICROHETER SITE DIAMETER

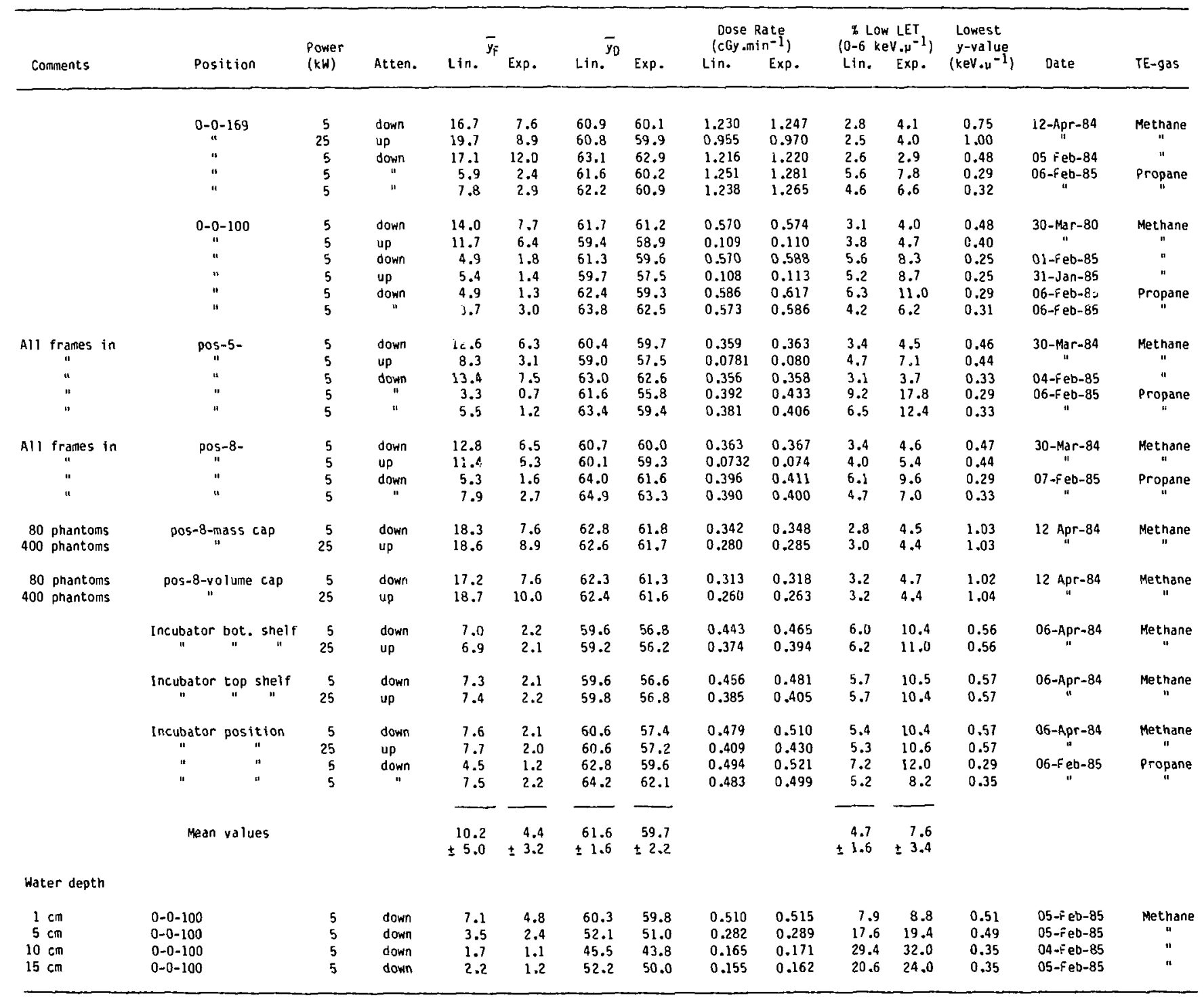




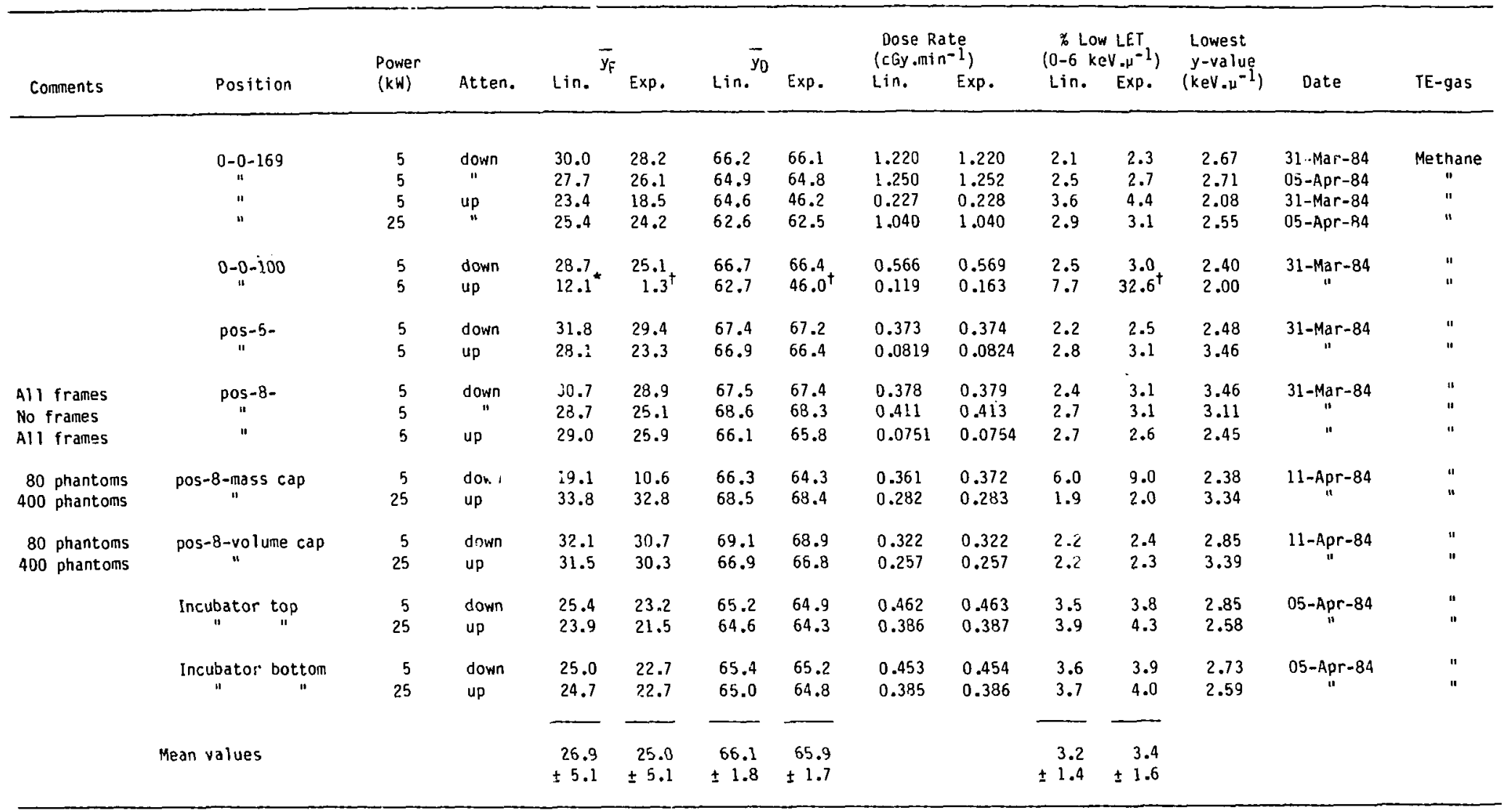

t Linear extrapolation was the best fit.

$t$ Value not included in the mean. 
TABLE 4.

5 MICROHETER SITE DIAMETER

\begin{tabular}{|c|c|c|c|c|c|c|c|c|c|c|c|c|c|c|}
\hline \multirow[b]{2}{*}{ Comments } & \multirow[b]{2}{*}{ Position } & \multirow{2}{*}{$\begin{array}{l}\text { Power } \\
(k W)\end{array}$} & \multirow[b]{2}{*}{ Atten. } & \multicolumn{2}{|c|}{$\bar{y}_{F}$} & \multicolumn{2}{|c|}{$\vec{y}_{D}$} & \multicolumn{2}{|c|}{$\begin{array}{l}\text { Dose Rate } \\
(\text { cGy.min-1) }\end{array}$} & \multicolumn{2}{|c|}{$\begin{array}{c}\% \text { LOW LET } \\
\left(0-6 \mathrm{keV}=\mathrm{\mu}^{-1}\right)\end{array}$} & \multirow{2}{*}{$\begin{array}{c}\text { Lowest } \\
y \text {-value } \\
\left(\mathrm{keV} . \mu^{-1}\right)\end{array}$} & \multirow[b]{2}{*}{ Date } & \multirow[b]{2}{*}{ TE-gas } \\
\hline & & & & Lin. & Exp. & Lin. & Exp. & Lin. & Exp. & Lin. & Exp. & & & \\
\hline & $\underset{41}{0-0-169}$ & $\begin{array}{l}5 \\
5\end{array}$ & $\begin{array}{l}\text { down } \\
\text { up }\end{array}$ & $\begin{array}{r}11.8 \\
8.4\end{array}$ & $\begin{array}{l}7.0 \\
3.4\end{array}$ & $\begin{array}{l}47.7 \\
45.3\end{array}$ & $\begin{array}{l}46.8 \\
43.1\end{array}$ & $\begin{array}{l}0.904 \\
0.165\end{array}$ & $\begin{array}{l}0.920 \\
0.174\end{array}$ & $\begin{array}{l}6.6 \\
9.1\end{array}$ & $\begin{array}{r}8.3 \\
13.5\end{array}$ & $\begin{array}{l}0.99 \\
0.99\end{array}$ & 28-Mar-84 & $\begin{array}{l}\text { Methane } \\
\text { " }\end{array}$ \\
\hline & $\underset{11}{0-0-100}$ & $\begin{array}{l}5 \\
5\end{array}$ & $\begin{array}{l}\text { do:tn } \\
\text { up }\end{array}$ & $\begin{array}{r}9.5 \\
10.3\end{array}$ & $\begin{array}{l}5.5 \\
5.3\end{array}$ & $\begin{array}{l}45.6 \\
45.1\end{array}$ & $\begin{array}{l}44.5 \\
43.7\end{array}$ & $\begin{array}{l}0.376 \\
0.0727\end{array}$ & $\begin{array}{l}0.386 \\
0.0751\end{array}$ & $\begin{array}{l}8.9 \\
8.6\end{array}$ & $\begin{array}{l}11.1 \\
11.5\end{array}$ & $\begin{array}{l}1.05 \\
1.38\end{array}$ & " & " \\
\hline Empty & pos-5- & $\begin{array}{l}5 \\
5\end{array}$ & $\begin{array}{l}\text { down } \\
\text { up }\end{array}$ & $\begin{array}{r}9.5 \\
10.2\end{array}$ & $\begin{array}{l}5.4 \\
6.9\end{array}$ & $\begin{array}{l}43.7 \\
43.7\end{array}$ & $\begin{array}{l}42.7 \\
43.1\end{array}$ & $\begin{array}{l}0.252 \\
0.0529\end{array}$ & $\begin{array}{l}0.258 \\
0.0540\end{array}$ & $\begin{array}{l}8.5 \\
8.3\end{array}$ & $\begin{array}{r}0.5 \\
9.6\end{array}$ & $\begin{array}{l}0.90 \\
0.90\end{array}$ & $"$ & " \\
\hline Empty & pos-8- & $\begin{array}{l}5 \\
5\end{array}$ & $\begin{array}{l}\text { down } \\
\text { up }\end{array}$ & $\begin{array}{r}9.0 \\
11.3\end{array}$ & $\begin{array}{l}5.4 \\
7.7\end{array}$ & $\begin{array}{l}43.9 \\
42.8\end{array}$ & $\begin{array}{l}42.9 \\
42.2\end{array}$ & $\begin{array}{l}0.261 \\
0.0494\end{array}$ & $\begin{array}{l}0.267 \\
0.0502\end{array}$ & $\begin{array}{l}9.1 \\
8.2\end{array}$ & $\begin{array}{r}11.2 \\
9.6\end{array}$ & $\begin{array}{l}1.0 \\
1.28\end{array}$ & " & " \\
\hline \multirow[t]{3}{*}{1 frame } & pos-8- & $\begin{array}{l}5 \\
5\end{array}$ & $\begin{array}{l}\text { down } \\
\text { up }\end{array}$ & $\begin{array}{r}9.3 \\
11.3\end{array}$ & $\begin{array}{l}5.6 \\
7.5\end{array}$ & $\begin{array}{l}42.8 \\
43.2\end{array}$ & $\begin{array}{l}41.8 \\
42.5\end{array}$ & $\begin{array}{l}0.245 \\
0.0483\end{array}$ & $\begin{array}{l}0.251 \\
0.0492\end{array}$ & $\begin{array}{l}9.1 \\
8.0\end{array}$ & $\begin{array}{r}11.1 \\
9.6\end{array}$ & $\begin{array}{l}0.99 \\
1.36\end{array}$ & $"$ & " \\
\hline & Incubator & $\begin{array}{l}5 \\
5\end{array}$ & $\begin{array}{l}\text { down } \\
\text { up }\end{array}$ & $\begin{array}{r}8.5 \\
10.5\end{array}$ & $\begin{array}{l}4.6 \\
5.9\end{array}$ & $\begin{array}{l}43.3 \\
43.4\end{array}$ & $\begin{array}{l}42.0 \\
42.6\end{array}$ & $\begin{array}{l}0.283 \\
0.0553\end{array}$ & $\begin{array}{l}0.292 \\
0.0560\end{array}$ & $\begin{array}{l}9.6 \\
8.5\end{array}$ & $\begin{array}{l}12.4 \\
10.1\end{array}$ & $\begin{array}{l}0.97 \\
1.22\end{array}$ & " & " \\
\hline & Mean & & & $\begin{array}{r}10.0 \\
\pm 1.1\end{array}$ & $\begin{array}{l}5 . \\
\pm 1.0\end{array}$ & $\begin{array}{r}44.2 \\
\pm \quad 1.4\end{array}$ & $\begin{array}{r}43.2 \\
\pm \quad 1.4\end{array}$ & & & $\begin{array}{r}8.5 \\
+0.8\end{array}$ & $\begin{array}{r}10.7 \\
\pm \quad 1.4\end{array}$ & & & \\
\hline
\end{tabular}


TABLE 5.

Ionisation chamber monitor readings

\begin{tabular}{|c|c|c|c|c|c|c|c|}
\hline Position & $\begin{array}{l}\text { Power } \\
\text { kW }\end{array}$ & Atten. & $\begin{array}{l}\text { Dose Rate } \\
(\text { cGy.min-1) }\end{array}$ & Position & $\begin{array}{l}\text { Power } \\
\mathrm{kW}\end{array}$ & Atten. & $\begin{array}{l}\text { Dose Rate } \\
\left(\text { cGy.min }{ }^{-1}\right)\end{array}$ \\
\hline $0-0-169$ & 5 & Down & 1.361 & Incubator & 5 & Down & 0.481 \\
\hline$"$ & 5 & Up & 0.272 &. & 5 & Up & 0.096 \\
\hline$"$ & 25 & Up & 1.139 & $"$ & 25 & Up & 0.403 \\
\hline $0-0-100$ & 5 & Down & 0.627 & Pos: 5,8 & 5 & Down & 0.435 \\
\hline$"$ & 5 & Up & 0.125 & $"$ & 5 & Up & 0.087 \\
\hline$"$ & 25 & Up & 0.525 & $"$ & 25 & Up & 0.364 \\
\hline
\end{tabular}


All Dimensions () in cm

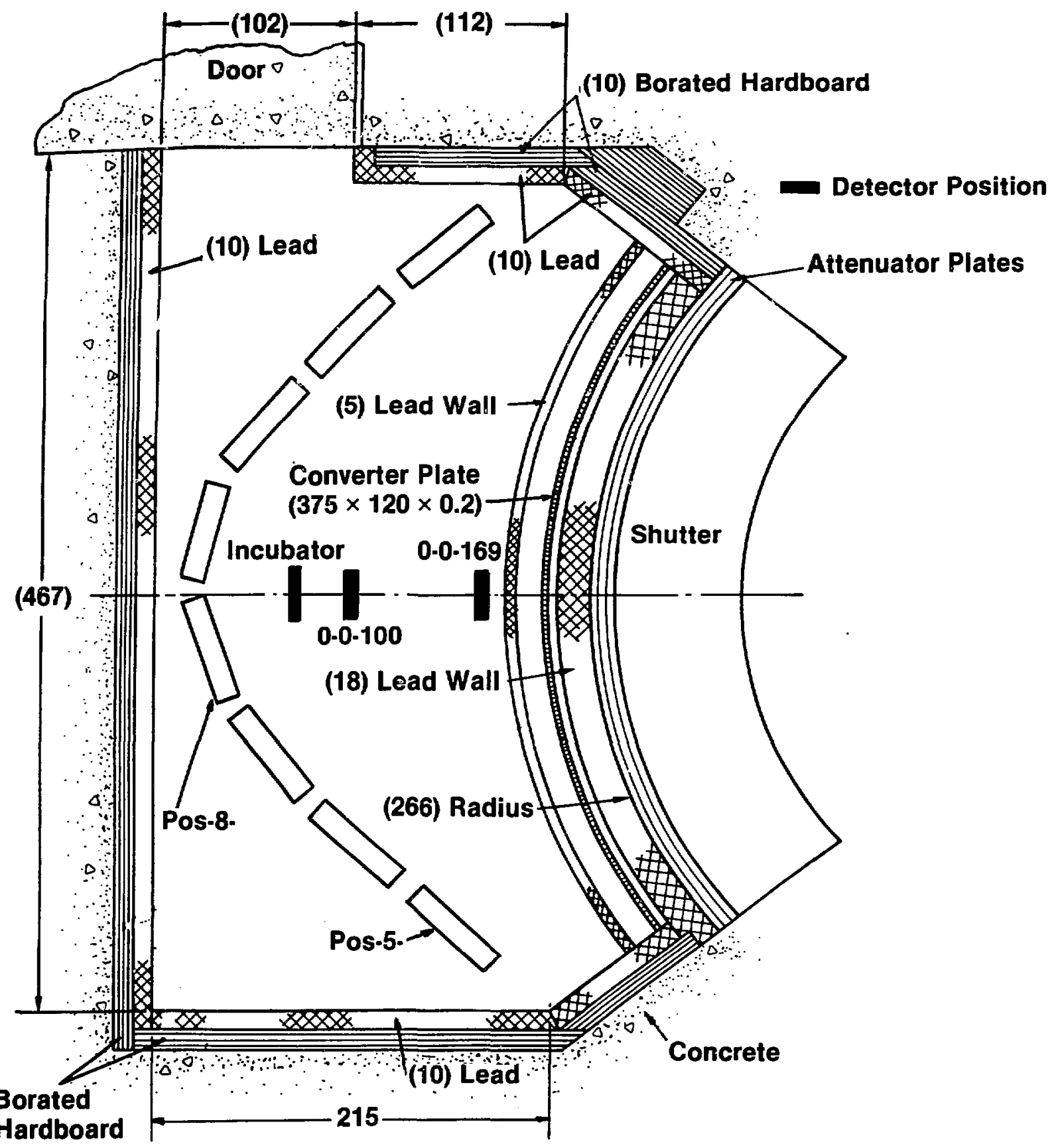

Figure ! 

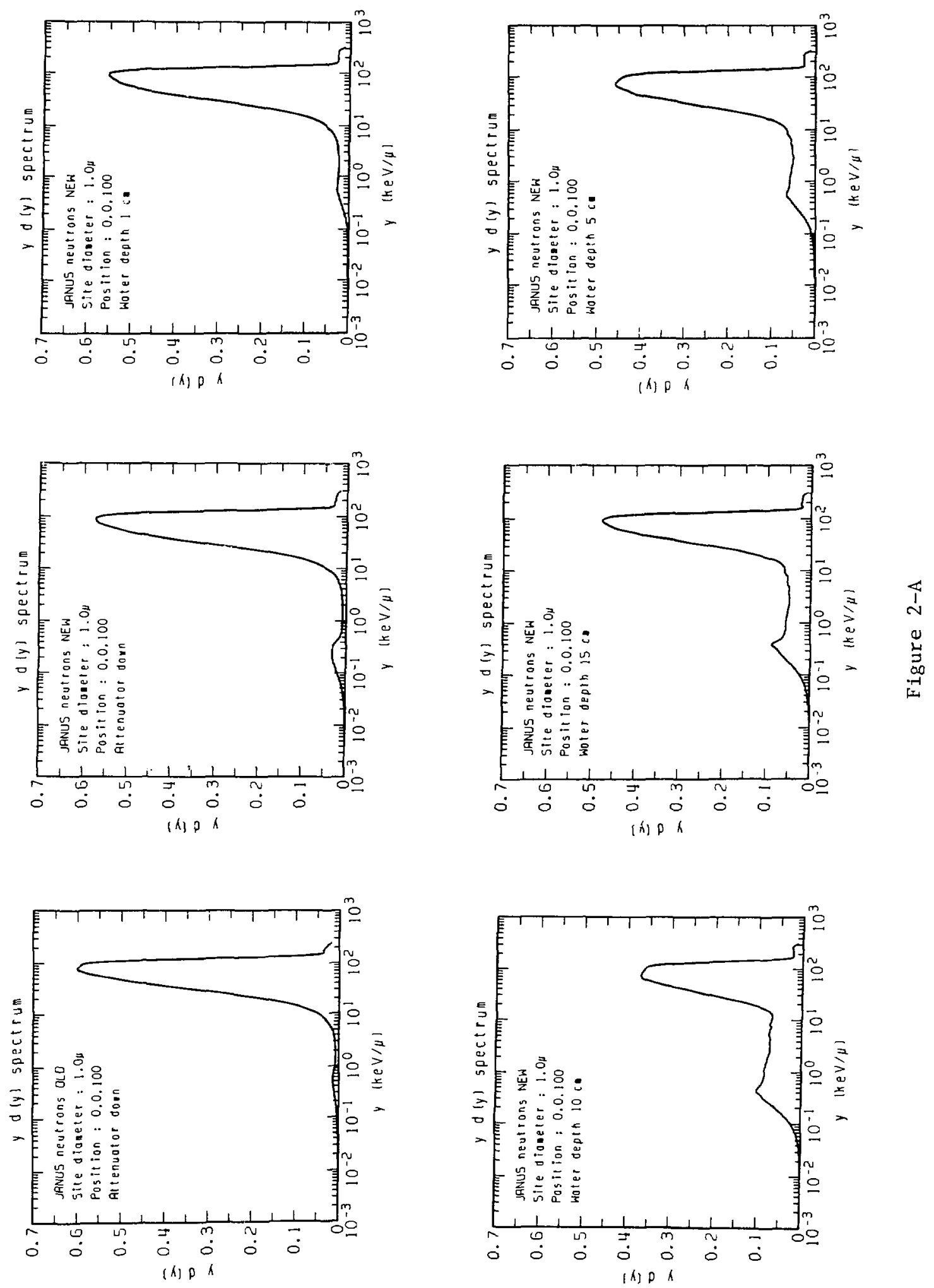

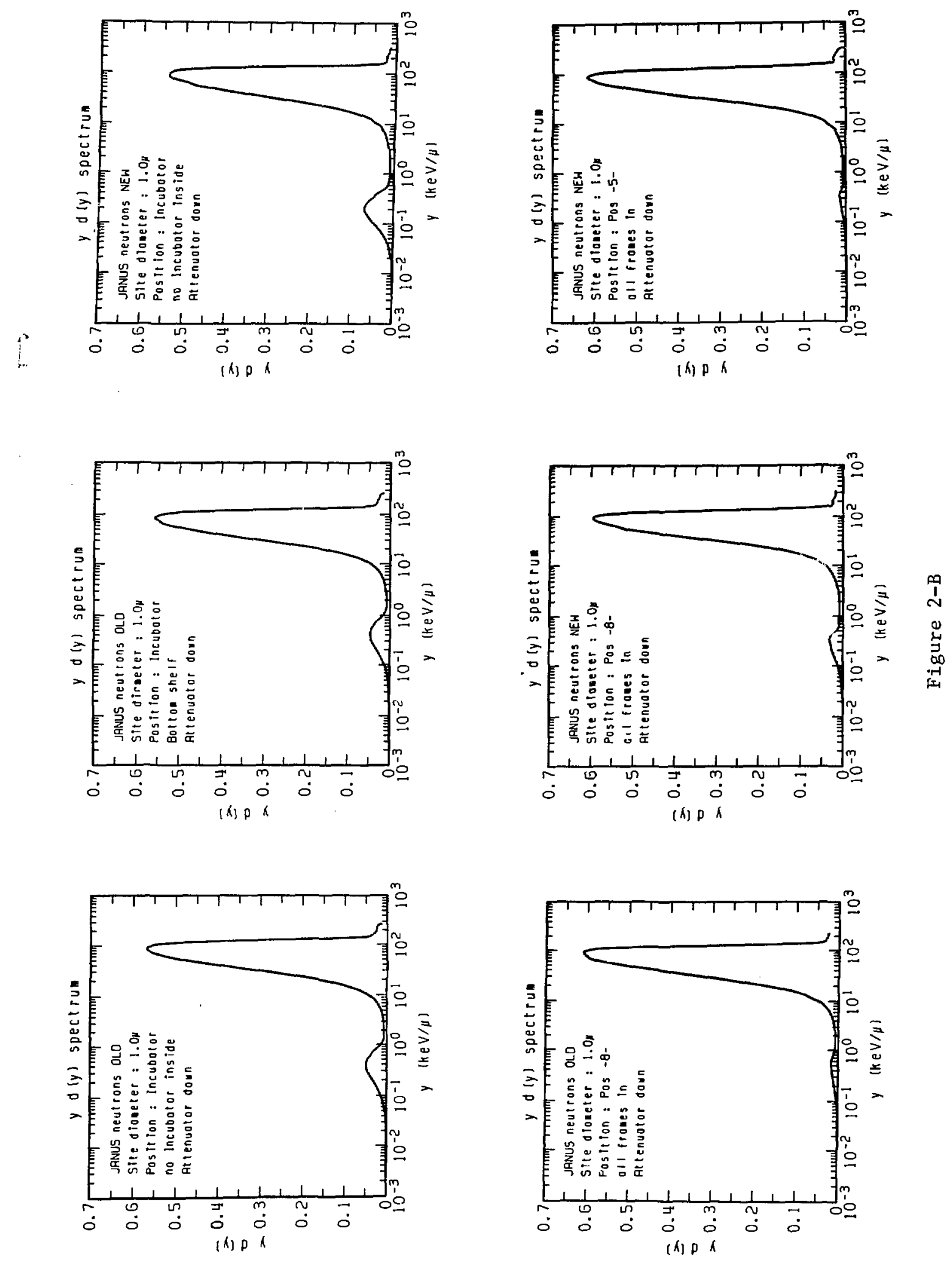
$y d(y)$ spectrua

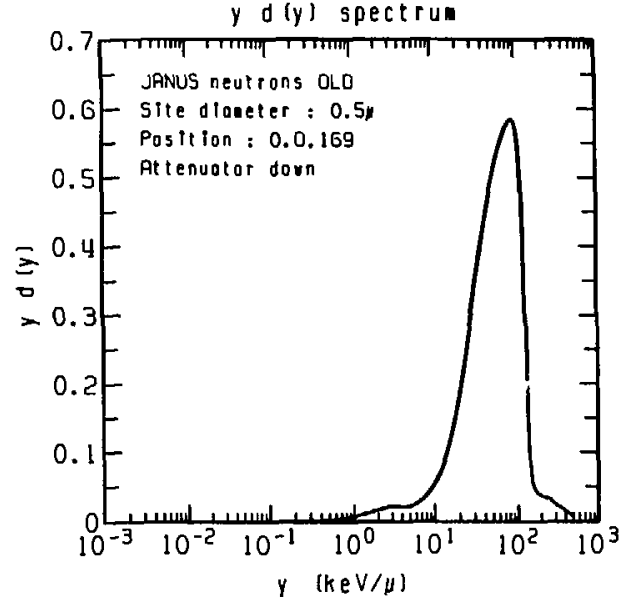

$y d(y)$ spectrun

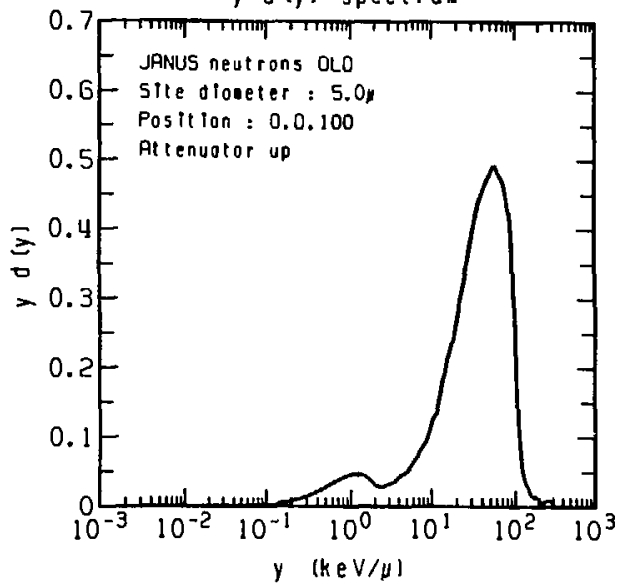

$y$ diyl spectrum

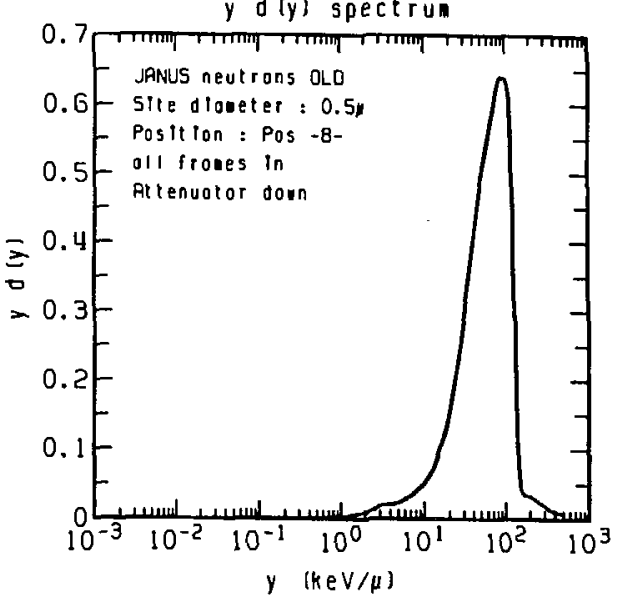

y $d(y)$ spectrus

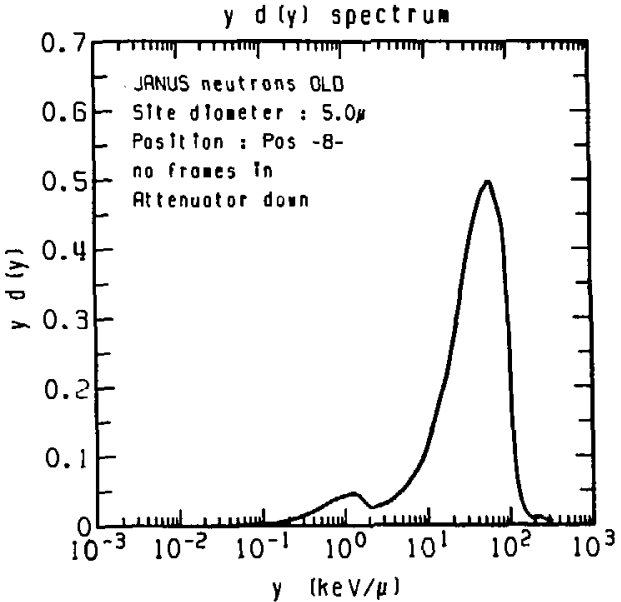

$y d(y)$ spectrun

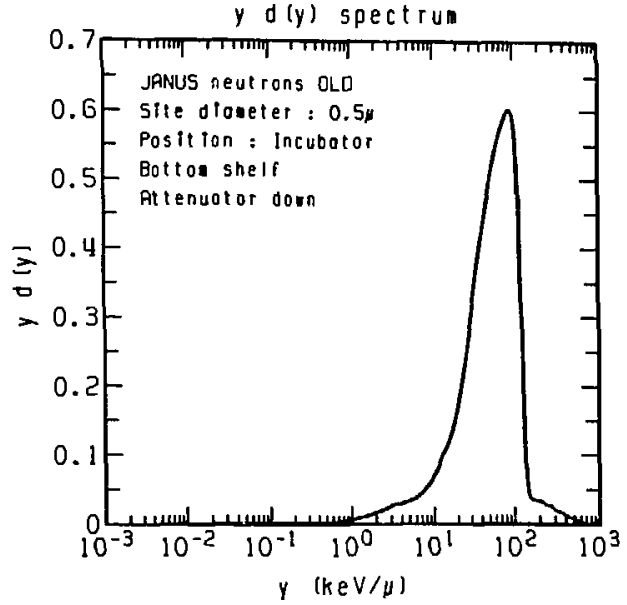

$y \quad f[y]$ spectrus

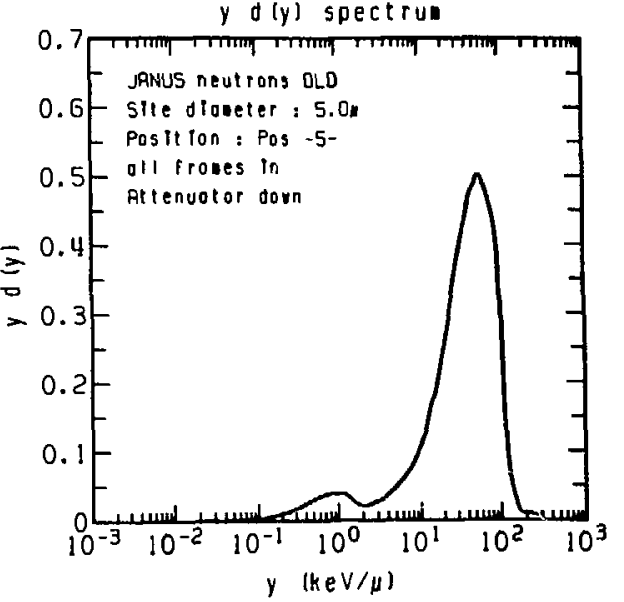

Figure 3 


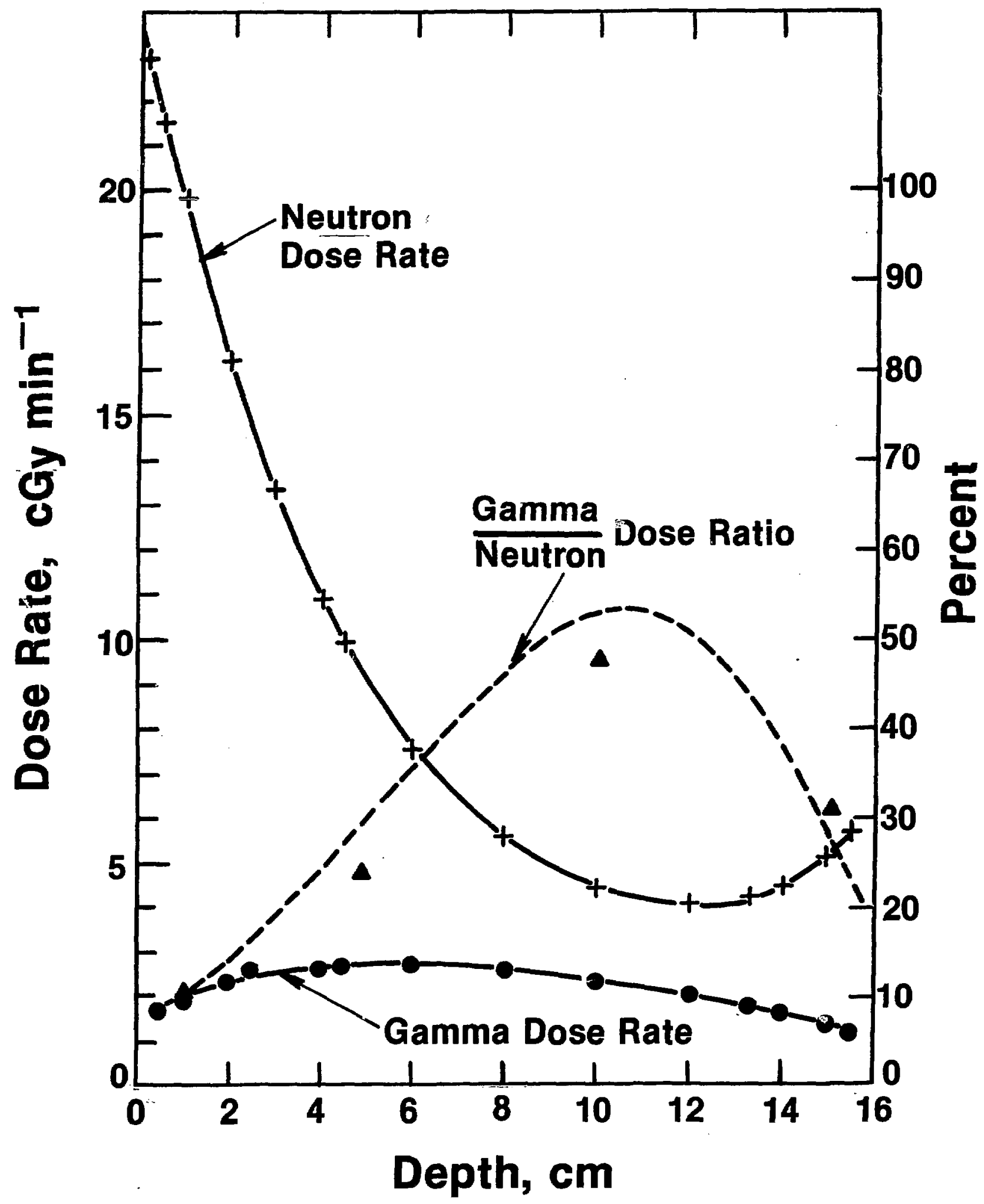

Figure 4 